\title{
From the Desk of the Editor
}

Much awaited Rainy Season has finally come albeit with widely varying intensity in different parts of India. It is expected that with the normal rain, economy of India, with its foundation lying greatly on rural agricultural and allied sectors, would see a ray of hope. Amidst this season with lushing green all around, Volume 86 No. 1 \& 2, January-June, 2016 issue of the Journal of the Association of Engineers, India is getting ready for its publication.

As the readers are by now habituated with the Column of the President of the Association, Prof. Dr. Madhusudan Bhattacharyya has penned a write-up containing the glimpse of his long experience and some of his feelings. Contributed papers included in this issue cover varying areas. These are ranging from 'Abrasive Water Jet Machining' to 'Performance Analysis of Leaf Spring' through A Novel Ancillary Braking System', 'Review on Cladding Techniques' and 'Newly Developed Carbon Nanotube Reinforced Alumina Tool Insert'. Hope the articles would be found interesting by the readers. Contents of the journal issues published in 2015 are included at the end of this journal for a ready reference.

The Contents of the journal is being circulated through Social Networking sites such as Facebook and Linkedin. Authors are requested to use 'ResearchGate' for circulating their papers widely among the world community. From this issue, plagiarism checking has been started using DupliCheck software. We have planned to start using Crosscheck software shortly. Abstracting service for all the available published articles will also be done shortly. We are going to start Abstracting service by assigning DOI number to each published article since the beginning. Contents of the journal volumes is being put into the Association website.

I sincerely thank contributors for submitting articles to this journal. I sincerely thank the Organising Secretary, Dr. Dipak Mandal and Dr. Chanan Syan of the 28th International Conference on CAD/CAM, Robotics and Factories of the Future (CAR \& FOF), 2016 held at College of Engineering and Management, Kolaghat, West Bengal for forwarding few papers for possible publication in the Journal. Honorable reviewers owe sincere acknowledgement for refereeing each article submitted to this journal. Comments and discussion on the published articles are welcome in the form of 'Letter to the Editor' to publish in the journal.

The regular column, 'Association News', lists different activities undertaken by the Association. Members and others may get involved in different activities of the Association. News of the sad demise of Prof. Dr. Subrata Pal is included in the 'Obituary'. The Membership Form of the Association is included at the end. New members are invited to get associated with this organisation which is approaching the Centenary Year in 2018. An organization can also become an Institutional Member by applying for the same on its letterhead.

Articles are invited for consideration for publication in the Journal of the Association of Engineers, India. Authors are requested to follow 'Author Guideline' given at the end of this issue. They would have to submit a 'Declaration' before publication of the article in the journal. A conference paper may also be published in this journal after appropriate extension and revision through the process of peer review. Conference organizers may contact the Editor in this regard. Detail of the Author Guideline, Declaration Form, Subscription Form and Advertisement Contract Form are available in the Association website, www.aeindia.org.in.

Wish you all the Best Season's Greetings!!

June 25, 2016

\section{Prof. Dr. Santanu Das}

The Editor

[Email : aei817@gmail.com] 